\title{
ARTIGO
}

DOI: $10.22481 /$ praxis.v14i28.3472

\section{A IMPORTÂNCIA DO PROFESSOR SUPERVISOR DE ESTÁGIO NA FORMAÇÃO DE FUTURAS PROFESSORAS DE MATEMÁTICA}

\author{
THE IMPORTANCE OF THE INTERNSHIP SUPERVISOR TEACHER IN THE \\ FORMATION OF FUTURE MATHEMATICS TEACHERS
LA IMPORTANCIA DEL PROFESOR SUPERVISOR DE PRÁCTICA EN LA FORMACIÓN DE FUTURAS PROFESORAS DE MATEMÁTICA

\author{
Jéssica Mistura Zanon \\ Universidade Estadual de Santa Cruz - Brasil \\ Maria Elizabete Souza Couto \\ Universidade Estadual de Santa Cruz - Brasil
}

\begin{abstract}
Resumo
Neste artigo apresentamos os resultados de uma investigação sobre a importância das ações do professor supervisor para a formação de futuras professoras da Educação Básica, durante a realização das atividades do estágio supervisionado em Matemática. Para isso, acompanhamos duas alunas de um curso de Licenciatura em Matemática de uma universidade pública, durante as atividades (regência) da disciplina Estágio Supervisionado III. Para a produção dos dados, utilizamos a observação (nas aulas de estágio na universidade e durante a regência nas escolas campo de estágio) e entrevistas (com as alunas/estagiárias e as professoras supervisoras na escola). Identificamos duas realidades, uma em que a estagiária teve o acompanhamento da professora supervisora durante todos os momentos do estágio e, a outra, uma estagiária que assumiu as turmas da professora, que poucas vezes esteve presente na sala de aula. Diante disso, evidenciamos que as duas, de acordo com cada realidade, construíram uma variedade de saberes - disciplinares (Matemática) e pedagógicos. Entretanto, o acompanhamento e supervisão do professor durante o estágio na escola são importantes, pois contribuem para reflexão e construção dos saberes docentes do aluno/estagiário em formação inicial, de modo que podem compartilhar experiências sobre a organização da classe, planejamento das aulas, relação com alunos, o ensino da Matemática etc. Aprendizagens que contribuem à construção dos saberes docentes.
\end{abstract}

Palavras-Chave: Formação inicial do professor de Matemática. Estágio supervisionado. Professor supervisor.

\begin{abstract}
In this article we present the results of an investigation about the importance of the actions of the supervising teacher for the formation of the future teacher of Basic Education during the supervised internship in Mathematics. For this, we accompany two students of the degree course in Mathematics of a public university, during the activities (regency) of the discipline Supervised Stage III. For the production of the data, we used observation (in the classes of internship in the university and in the development of the regencies in the schools field of internship) and semi-structured interviews (with the students / trainees and with the supervisory teachers in the school). We identified two different realities, one in which the trainee was supervised by the supervising teacher during all stages of the
\end{abstract}


traineeship, and in the other, a trainee who took over the classes of the teacher, who was rarely present in the classroom. In view of this, we have shown that the two, according to each reality, have built a variety of disciplinary (mathematics) and pedagogical knowledge. But the monitoring and supervision of the teacher during the internship in the school / classroom are important, because they contribute to the reflection and construction of the teacher's knowledge of the student / trainee in initial formation, so they can share experiences about class organization, lesson planning, student relationships, mathematics teaching, and so on. Learning that contributes to the construction of teaching knowledge.

Keywords: Initial formation of the Mathematics teacher. Supervised internship. Supervisory teacher.

\section{Resumen}

En este artículo presentamos los resultados de una investigación sobre la importancia de las acciones del profesor supervisor para la formación del futuro profesor de Educación Básica, durante la realización de las actividades de la práctica supervisada en Matemáticas. Para ello, acompañamos a dos alumnas de un curso de Licenciatura en Matemáticas de una universidad pública, durante las actividades (regencia) de la disciplina Práctica Supervisada III. Para la producción de los datos, utilizamos la observación (en las enseñanza de práctica en la universidad y en el desarrollo de las regencias en las escuelas campo de práctica) y entrevistas semiestructuradas (con las alumnas / pasantes y con las maestras supervisoras en la escuela). Identificamos dos realidades diferentes, una de ellas en que la pasante tuvo el acompañamiento de la profesora supervisora durante todos los momentos del práctica y, en la otra, una pasante que asumió las clases de la profesora, que pocas veces estuvo presente en el enseñanza. En este sentido, evidenciamos que las dos, de acuerdo con cada realidad, construyeron una variedad de saberes - disciplinares (matemáticos) y pedagógicos. Pero el acompañamiento y supervisión del profesor durante la etapa en la escuela / clase son importantes, que contribuyen a la reflexión y construcción de los saberes docentes del alumno / pasante en formación inicial, de modo que puedan compartir experiencias sobre la organización de la clase, planificación de las clases, relación con alumnos, la enseñanza de las Matemáticas, etc. Aprendizajes que contribuyen a la construcción de los saberes docentes.

Palabras clave: Formación inicial del profesor de matemáticas. Práctica supervisada. Profesor supervisor.

\section{Introdução}

No contexto da formação inicial do professor, o Estágio Supervisionado é considerado como uma etapa que contribui para a aprendizagem da docência, pois, entende-se que os alunos, futuros professores, estão construindo um repertório de conhecimentos que lhes favorecem o exercício da profissão. Isso propicia ao aluno/estagiário vivenciar o dia a dia da profissão, observando e compartilhando conhecimento com um professor mais experiente, conhecendo a realidade da sala de aula, dos alunos, da escola etc. Tais aprendizagens já foram evidenciadas nos estudos e pesquisas que discutem essa etapa da formação, dentre os quais podemos destacar Barreiro e Gebran (2006), Passerini (2007), Pimenta e Lima (2010) entre outros. 
Nesse sentido, entre os aspectos legais que norteiam a realização do Estágio Supervisionado nos cursos superiores, temos as Diretrizes Curriculares Nacionais para os cursos de Matemática que o indicam como etapa fundamental nos cursos de formação de professores, pois possibilita desenvolver:

a) uma seqüência de ações onde o aprendiz vai se tornando responsável por tarefas em ordem crescente de complexidade, tomando ciência dos processos formadores;

b) uma aprendizagem guiada por profissionais de competência reconhecida (BRASIL, 2001, p. 6).

Dessa forma, o estágio é um momento de aprendizagens e desenvolvimento da docência (MIZUKAMI, 2006), no qual é importante que o aluno/estagiário tenha o acompanhamento de professores experientes, ou seja, os professores da universidade e os professores supervisores do estágio (na escola). Pois, são esses professores, que irão orientar as ações dos alunos/estagiários na escola e, além disso, mediarão os processos de reflexão e produção de saberes docentes.

Nesse contexto, temos como objetivo neste artigo apresentar os resultados de uma investigação sobre a importância das ações do professor supervisor ${ }^{1}$ para a formação do futuro professor da Educação Básica, durante a realização das atividades do estágio supervisionado em Matemática.

O estudo em questão foi desenvolvido em um curso presencial de Licenciatura em Matemática de uma universidade pública do sul da Bahia, na disciplina Estágio Supervisionado III, que ocorreu no semestre 2016.2. Nesse curso, o estágio supervisionado é dividido em quatro disciplinas, sendo que, no Estágio Supervisionado I o aluno observa o ambiente escolar e desenvolve atividades de monitoria na sala de aula; no Estágio Supervisionado II, realiza oficinas com alunos da Educação Básica; no Estágio Supervisionado III realiza a regência no Ensino Fundamental e, no Estágio Supervisionado IV, a regência no Ensino Médio. De acordo com o projeto do curso, essas atividades devem ser acompanhadas e orientadas pelo professor supervisor da escola e pelo professor da disciplina de estágio na universidade.

\footnotetext{
${ }^{1}$ Professor supervisor é o professor regente da disciplina Matemática, da escola de Educação Básica, que recebe o aluno/estagiário em sua sala de aula.
} 
Assim, durante a investigação, observamos o desenvolvimento das atividades de regência nas escolas da educação básica (campo de desenvolvimento das atividades de estágio), em classes dos anos finais do Ensino Fundamental.

Tendo em vista o nosso objetivo, inicialmente apresentamos os procedimentos metodológicos traçados para a realização dessa pesquisa. Em seguida, fazemos uma discussão teórica sobre o estágio supervisionado, como um momento de mobilização de saberes docentes pelo futuro professor de Matemática, por meio da parceria entre o aluno/estagiário e o professor supervisor de estágio. Depois, apresentamos o desenvolvimento da atividade de estágio, considerando a importância da parceria entre as professoras supervisoras e as alunas/estagiárias. Por fim, as nossas considerações finais.

\section{O Percurso da pesquisa}

O estudo aqui apresentado teve uma abordagem qualitativa, o que nos possibilitou descrever comportamentos e ações, investigar interações, colher significados, interpretar e compreender linguagens, analisar representações, tudo isso sem desprendê-los do contexto e das circunstâncias em que se manifestaram.

O contexto da pesquisa refere-se ao curso de Licenciatura em Matemática focalizando a disciplina Estágio Supervisionado III e os oito alunos matriculados. Na primeira aula da disciplina, pedimos que respondessem um questionário, com informações sobre ingresso no curso, experiência docente, a escola escolhida para realização do estágio e disponibilidade para participar da pesquisa. Dos oito estudantes, quatro disponibilizaram-se para participar da pesquisa. Considerando os critérios de: não experiência docente ensinando Matemática, ou seja, para quem o estágio foi a primeira experiência ensinando essa disciplina no ambiente da escola e, a oportunidade de acompanhar as aulas durante a regência do estágio, selecionamos para a escrita desse artigo os dados produzidos durante a investigação do estágio de duas alunas/estagiárias.

As alunas/estagiárias, que foram chamadas de Ana e Isa, no período de produção do material empírico cursaram a disciplina Estágio Supervisionado III, no semestre 2016.2, juntamente com as professoras supervisoras do estágio nas escolas - Inês e Vera. As participantes assinaram o Termo de Consentimento Livre e Esclarecido (TCLE) e foram identificadas por nomes fictícios, como critério de preservação da identidade. 
A pesquisa ocorreu na universidade (campo de formação docente) e em duas escolas públicas da Educação Básica (campo de desenvolvimento das atividades de estágio supervisionado do curso de Licenciatura em Matemática), escolhidas por Ana e Isa para realização do estágio.

Um fator que também nos influenciou na escolha das participantes refere-se ao acompanhamento e supervisão das professoras nas escolas campo de estágio, tendo em vista que Isa teve o acompanhamento da professora Vera durante o período de realização da regência, enquanto que Ana assumiu duas turmas da professora Inês, que não a acompanhou presencialmente nas atividades em sala de aula. A partir dessas duas realidades, analisamos como foram as aprendizagens das alunas/estagiárias e como as professoras supervisoras contribuíram nesse processo.

A estagiária Ana ingressou no curso de Licenciatura em Matemática em 2013.1 e tem previsão de conclusão para 2017.2. Não possui experiência docente na disciplina de Matemática, mas, já lecionou nos anos iniciais do Ensino Fundamental (para crianças de cinco e seis anos de idade) durante cinco anos, na época em que o magistério habilitava para ensinar nessas turmas. Sempre teve afinidade com a Matemática e foi dando as aulas particulares de Matemática para alunos da Educação Básica que encontrou a motivação para iniciar um curso de licenciatura.

A estagiária Isa ingressou no curso de Licenciatura em Matemática em 2011.1 e concluiu em 2017.1. Não possui experiência docente na disciplina Matemática, mas, por ter facilidade com a disciplina, relatou que ajudava seus professores quando ainda cursava o Ensino Médio, fazendo monitorias e, até mesmo, os substituindo quando precisavam se ausentar. Nos vestibulares, Matemática sempre foi sua primeira opção.

A professora Inês foi a supervisora da estagiária Ana. É graduada em Ciências Econômicas, profissão que atuou por 15 anos. Depois, resolveu cursar Licenciatura em Matemática e se especializou na área de Educação Matemática com ênfase em Tratamento da Informação e Estatística. Possui 25 anos de experiência docente e sempre ensinou Matemática. É professora efetiva em uma escola pública da rede estadual da Bahia. Atualmente, leciona no $6^{\circ}$ e $7^{\circ}$ ano do Ensino Fundamental e aguarda deferimento da aposentadoria.

A professora Vera foi supervisora da estagiária Isa. É formada em Matemática, com especialização em História da Matemática. Exerce a docência há 21 anos, mas, nem sempre atuou na disciplina Matemática. Lecionava nos anos iniciais do Ensino Fundamental, quando 
era habilitada pelo magistério, depois, entre a década de 80 e 90, fez um curso oferecido pelo município que reside e atua, chamado "Caxiense", que habilitava para lecionar Matemática para $5^{\mathrm{a}}$ e $6^{\mathrm{a}}$ séries. Com essa oportunidade, passou a gostar de ensinar Matemática e, mais tarde, já nos anos 2000, conheceu e frequentou o curso chamado Pró-formação, oferecido pelo Governo do Estado da Bahia em parceria com uma Universidade Estadual. A partir da conclusão desse curso (2006), continuou ensinando Matemática. Atualmente, leciona em uma turma do $9^{\circ}$ ano do Ensino Fundamental e na $1^{\mathrm{a}}, 2^{\mathrm{a}}$ e $3^{\mathrm{a}}$ série do Ensino Médio.

Para o contato com as escolas campo de estágio, estabelecemos uma parceria com a professora da universidade (que lecionou a disciplina Estágio Supervisionado III), que nos apresentou à direção das escolas e às professoras supervisoras, solicitando a permissão para o desenvolvimento da pesquisa.

Para a produção do material empírico da pesquisa utilizamos as seguintes técnicas: observação (nas aulas de Estágio Supervisionado III e no desenvolvimento das atividades/aulas nas escolas campo de estágio), a fim de vivenciar a realidade do estágio e entrevistas semi-estruturadas (com as alunas/estagiárias - Ana e Isa e com as professoras supervisoras na escola - Inês e Vera), para compreender como a disciplina Estágio Supervisionado contribui com a formação inicial do professor de Matemática.

Realizamos uma entrevista com as professoras e duas com as alunas/estagiárias, uma no início do Estágio Supervisionado III e a outra após a conclusão da atividade de regência. Depois, transcrevemos as entrevistas e fizemos uma textualização, de forma a organizar o texto e retirar palavras desnecessárias, para deixar o texto mais claro. Por fim, encaminhamos para as entrevistadas, para que pudessem validar o texto para utilizarmos em nossos estudos.

As observações foram registradas em uma ficha de observação, na qual nos atentamos para a relação entre professoras supervisoras e a alunas/estagiárias; as aprendizagens e mobilização de saberes oportunizados durante o estágio e, as discussões na universidade (espaço de reflexão da prática docente). Essas observações nas aulas de Estágio Supervisionado III, foram realizadas semanalmente, no semestre 2016.2 , no período ${ }^{3}$ de 08/09/16 a 25/01/17, totalizando seis aulas. Nessa disciplina, a proposta foi que os alunos cumprissem dez horas de observação na sala de aula, 30 de regência, em turmas dos anos finais do Ensino Fundamental e as outras 50 horas, na universidade.

\footnotetext{
${ }^{2}$ São Estudos Adicionais ao Magistério de $1^{\circ}$ Grau ofertado pelo Centro de Estudos Caxiense - Salvador-Ba.

${ }^{3}$ É importante informar, que a Universidade teve suas atividades suspensas em virtude do Movimento de Ocupação dos estudantes universitários, que perdurou por 54 dias (25/10 à 17/12/16).
} 
Para observar a regência das aulas de Isa e Ana, nos organizamos de forma a conseguir acompanhá-las o máximo possível, conforme o Quadro 1.

Quadro 1: Distribuição das aulas das estagiárias nas escolas observadas por nós

\begin{tabular}{|c|c|c|c|}
\hline \multicolumn{2}{|c|}{ Ana $\left(6^{\circ}\right.$ ano $)$} & \multicolumn{2}{|c|}{ Isa ( $\left(9^{\circ}\right.$ ano) } \\
\hline Dia & Qtd. de aulas & Dia & Qtd. de aulas \\
\hline $18 / 10 / 16$ & 03 aulas & $26 / 10 / 16$ & 02 aulas \\
\hline $20 / 10 / 16$ & 02 aulas & $31 / 10 / 16$ & 01 aula \\
\hline $27 / 10 / 16$ & 02 aulas & $01 / 11 / 16$ & 01 aula \\
\hline $03 / 11 / 16$ & 02 aulas & $07 / 11 / 16$ & 01 aula \\
\hline $17 / 11 / 16$ & 02 aulas & $09 / 11 / 16$ & 02 aulas \\
\hline & & $16 / 11 / 16$ & 02 aulas \\
\hline & & $23 / 11 / 16$ & 02 aulas \\
\hline & & $30 / 11 / 16$ & 02 aulas \\
\hline
\end{tabular}

Fonte: Material produzido na pesquisa (2015/2017).

A partir dos dados produzidos nas observações e nas entrevistas, iniciamos a análise. Para isso, transcrevemos as entrevistas e observações e, em seguida, fizemos a leitura, para destacar os aspectos referentes às aprendizagens docentes e experiências oportunizadas entre as alunas e as professoras supervisoras. Para validação desses dados, utilizamos a metodologia de triangulação, pela qual buscamos relacionar as seguintes fontes: o referencial teórico que nos embasou na pesquisa e o material das entrevistas e observações, por considerarmos que tal metodologia ajudou-nos a compreender o objeto de estudo.

\section{O estágio supervisionado e a mobilização de saberes docentes}

O estágio supervisionado é uma das etapas da formação inicial que visa a aproximar os alunos do seu futuro ambiente de trabalho. Para isso, exige o envolvimento de várias pessoas nesse processo de formação: alunos, professores da universidade e da escola de educação básica, coordenação do curso, entre outros. Todos guiados pelo mesmo objetivo, o desenvolvimento profissional do futuro professor. Nesse sentido, consideramos que as ações do professor supervisor do estágio, na escola, são importantes para que esse momento atinja seu objetivo formador, que o aluno/estagiário seja acompanhado/orientado para desenvolver as atividades docentes, tenha a oportunidade de viver o contexto da escola e comece a aprender a ser professor com um professor experiente.

Pimenta e Lima (2010) destacam a docência como qualquer outra profissão, isto é, aprender a ser professor também é uma ação, uma prática, pois essa aprendizagem vem a 
partir da observação, imitação, reprodução e reflexão, em que o aluno irá aprender a ser professor e, assim, elaborar seu próprio perfil.

Segundo Barreiro e Gebran (2006) o estágio, bem como a formação inicial, deve relacionar-se com a investigação da realidade, com uma prática intencional, possibilitando que as ações sejam marcadas por processos de reflexão entre professores e futurosprofessores, na medida em que, por meio dessa reflexão, examinem, questionem e avaliem criticamente o seu fazer, o seu pensar e a sua prática. Com isso, vão se constituindo enquanto futuro professor, ao incorporarem tais ações à futura prática ou descartarem aquelas que não lhes pareçam adequadas. Assim, "todo professor, ao iniciar sua carreira, vai fazer na sala de aula, basicamente, o que ele viu alguém, que o impressionou, fazendo. E vai deixar de fazer algo que viu e não aprovou" (D’AMBROSIO, 2009, p. 91).

Dessa forma, podemos dizer, que o aluno/estagiário que terá a sua primeira experiência no ambiente escolar e na regência de aulas de Matemática, poderá planejar suas aulas pensando nas vivências que já teve, anteriormente, enquanto aluno, com aqueles professores que lhe marcou, nas metodologias que funcionaram etc. Até mesmo nas experiências que já teve durante o próprio estágio, ao observar as aulas de professores mais experientes.

Para Passerini (2007), o estágio supervisionado possibilita uma aproximação do aluno com seu futuro ambiente de trabalho e pode proporcionar que faça análises sobre a realidade escolar, o que pode estimular o desenvolvimento de novos métodos de ensino e fazer com que pense sobre o que é ensinar. Tais ações contribuem para que os futuros professores lancem um 'novo olhar' sobre o ensino, a aprendizagem, as práticas docentes, além de ser também um momento para se consolidar os conhecimentos adquiridos nas diversas disciplinas do curso e a mobilização de diversos saberes.

Com relação a esses saberes que são mobilizados durante a formação do professor, Tardif (2002) considera que é algo particular e está relacionado com diversos fatores, tais como a identidade do professor, experiência de vida, história profissional e a relação com os alunos e com os outros profissionais da escola. Não é um saber acabado, pois vai sendo construído ao longo de sua carreira profissional. Nesse sentido, ensinar é mobilizar uma variedade de saberes, que para esse autor, são definidos como saberes profissionais, disciplinares, curriculares e experienciais.

De acordo com Tardif (2002), os saberes profissionais são transmitidos pelas instituições formadoras - a universidade -, a fim de incorporá-los à prática do professor. Esses 
saberes se dividem em científicos (formação científica) ou pedagógicos (surgem das reflexões sobre a prática docente). Os saberes disciplinares correspondem aos diversos conhecimentos que também são transmitidos nos cursos e departamentos universitários, são os saberes das disciplinas (por exemplo, Matemática, História, Literatura etc.). Os saberes curriculares referem-se aos discursos, objetivos, conteúdos e metodologias, em suma, são os programas escolares que os professores devem desenvolver em suas salas de aula.

Com relação aos saberes experienciais, também chamados de práticos, Tardif (2002) caracteriza como aqueles produzidos a partir do exercício e da prática da profissão, ou seja, baseados no cotidiano da profissão docente. Esses saberes não são desenvolvidos nas instituições formadoras, mas sim na própria ação do professor. Nesse caso, começa a partir do momento que inicia a docência, o que pode acontecer desde o estágio. Para este autor,

[...] o relacionamento dos jovens professores com os professores experientes, os colegas com os quais trabalhamos diariamente ou no contexto de projetos pedagógicos de duração mais longa, o treinamento e a formação de estagiários e de professores iniciantes, todas essas são situações que permitem objetivar os saberes da experiência. (TARDIF, 2002, p. 52).

Assim, é importante para o futuro professor essa troca de saberes com professores experientes, visto que já passaram por muitas situações em sua carreira profissional e isso lhes proporcionou criar um repertório de conhecimentos que norteiam sua ação. Enquanto que os alunos/futuros professores, tiveram pouca ou nenhuma experiência docente no cotidiano escolar. Nesse sentido, Tardif (2002, p. 53) propõe que são vários os saberes que os professores experientes podem compartilhar, tais como "dos macetes, dos modos de fazer, dos modos de organizar a sala de aula", além disso, podem também dar dicas sobre o comportamento dos alunos, de como lidar com a indisciplina etc.

Barreiro e Gebran (2006) também indicam a necessidade de um professor supervisor presente no estágio, pois um professor experiente será o mediador de momentos de reflexão, análise e interpretação da realidade educacional do campo do estágio e, a partir dessas vivências e experiências, o estagiário irá construindo sua prática e o conhecimento da docência.

Todavia, a organização dos estágios supervisionados na estrutura dos cursos, parece que ainda encontra algumas barreiras e, por vezes, nem sempre atingem o seu potencial formador, situação evidenciada nas reflexões de Varizo (2006), quando indica que, na maioria dos cursos de licenciatura, os estágios supervisionados ficam isolados, pois não há um 
supervisor que acompanhe o estagiário nas escolas e faça as devidas orientações sobre como deve agir neste ambiente.

Assim, o professor supervisor do estágio possui um papel importante, que se inicia antes do aluno/estagiário desenvolver suas atividades de estágio, ou seja, durante o planejamento das ações. Seu papel permanece durante a realização das atividades, orientando e fazendo intervenções, quando necessário, e conclui após a realização das atividades, juntamente com o aluno/estagiário, mediando os momentos de reflexões sobre as experiências vivenciadas em sala de aula, oportunizando, assim, a construção dos saberes docentes.

Moura (2011, p. 10) indica, que os educadores, ao ensinarem Matemática, "estão ensinando não apenas um conteúdo, mas um modo de apreender conteúdos, isto é, uma metodologia de interagir no mundo, própria do saber pedagógico". Podemos inferir que para ser um professor de Matemática, não basta apenas conhecer e saber transmitir fórmulas e teoremas, da forma tradicional que alguns cursos de licenciatura ainda hoje ministram, mas, contextualizar esse conhecimento matemático para dar vida e função social aos números, fórmulas e teoremas. Por isso, parece ser preciso repensar essa formação inicial do professor de Matemática.

Pensando nisso, Lübeck e Souza (2012) refletem que a formação das licenciaturas em Matemática apoiadas somente no conhecimento técnico, tem-se mostrado ineficazes para o ensino de Matemática, sendo importante conhecer as diversas inter-relações que existem entre os conteúdos do currículo matemático e o conhecimento de uma maneira geral. Dessa forma, os cursos devem possibilitar um saber disciplinar (Matemática) relacionado com situações do cotidiano para o ensino na Educação Básica, pois é o contexto onde o futuro professor, possivelmente, irá atuar.

Sobre os saberes que o professor mobiliza ao ensinar, Mizukami (2006) os caracteriza em três eixos essenciais de conhecimento/aprendizagem para a docência. São conhecimentos sobre:

a) os alunos, seus processos de desenvolvimento e seus contextos socioculturais, o que envolve conhecimento sobre aprendizagem, desenvolvimento humano e aquisição e desenvolvimento da linguagem; b) a matéria que os professores ensinam e o currículo em face de objetivos educacionais mais amplos e c) o ensino de diferentes matérias, de diferentes alunos, de formas de avaliação e de manejo de classe (MIZUKAMI, 2006, p. 215, grifos do original).

O conhecimento referente aos alunos está relacionado a forma como eles aprendem, que deve levar em consideração suas fraquezas, interesses, pré-conceitos, além disso, deve 
pensar, também, no conhecimento que se pretende que aprendam, a forma de avaliar a aprendizagem e os espaços onde ocorre, seja dentro ou fora da escola. Nesse sentido, Tardif (2002) considera que os alunos são 'objetos de trabalho' heterogêneos, pois possuem características individuais. Sobre a aprendizagem, por exemplo, o professor poderá se deparar com uma turma em que cada aluno terá uma capacidade e até mesmo um ritmo, 'tempo de aprendizagem' diferentes. Vão existir também as diferenças de origem social, étnica, cultural e econômica. Essas questões precisam ser levadas em consideração, desde o momento da formação inicial, pelo professor ao ensinar/formar, por isso, é importante que conheça cada um de seus alunos.

Quando essas diferenças aparecem, o professor precisa desenvolver uma característica, indicada por Tardif (2002), o controle da turma. Um controle que deve ser assumido pelo professor não no sentido de se opor, mas sim de buscar formas de harmonizar as resistências dos alunos. Dessa forma, o professor precisa criar meios de motivá-los a aprender, assim, possivelmente irá amenizar as situações de indisciplina em sala de aula e conseguirá manter o controle da turma, resultando na aprendizagem.

Nesse sentido, Tardif (2002) sugere três técnicas que podem ser desenvolvidas pelo professor, que facilitarão sua atuação e interação com os alunos, a saber: a coerção, a autoridade e a persuasão. A coerção, considerada na sua forma simbólica, consiste em um comportamento punitivo, de forma a determinar os limites para os alunos, geralmente remete a atitudes de exclusão, sarcasmo, ironia, isolamento etc., ou seja, ações que visam punir os alunos para que não repitam determinado comportamento. A autoridade está relacionada ao respeito que o professor recebe de seus alunos, o que, muitas vezes, também está relacionado ao seu carisma e afetividade, sendo assim, desnecessária a coerção. Já a persuasão, consiste em convencer o aluno a fazer ou acreditar em algo, ou seja, é a forma como o professor fala com os alunos objetivando convencê-los. Nesse momento, essa relação entre professor e aluno, pode variar, a depender dos argumentos que o professor utiliza para convencer os alunos. Ele precisa ter essa capacidade para dizer ao aluno, por exemplo, 'porque ele precisa aprender aquele conteúdo’ ou 'qual é a importância daquele outro conteúdo', utilizar os argumentos corretos para demonstrar a função social dos conteúdos para a vida do aluno.

Com relação ao segundo eixo, 'a matéria que os professores ensinam', Mizukami (2006) sugere que o professor deve conhecer a matéria que ensina e compreender como o currículo está organizado, quanto às especificidades dos alunos, das escolas e dos objetos de aprendizagem. Dessa forma, mais que conhecer o conteúdo que está ensinando, o professor 
precisa conhecer o porquê de ensinar e os objetivos que se pretende alcançar. Para traçar esses objetivos é necessário saber para quem está ensinando, quais as necessidades dos alunos, qual o contexto em que estão inseridos. Questões que influenciarão no planejamento do conteúdo e da aula.

Por fim, quanto ao terceiro eixo, "o ensino de diferentes matérias", a autora sugere que o professor, além de dominar o conhecimento específico de sua área, ou seja, sua matéria, deve também possuir no mínimo quatro tipos de conhecimento de outras áreas, tais como conhecimento pedagógico do conteúdo específico que ensina, conhecimento de como ensinar para uma diversidade de alunos, conhecimento de como avaliar a aprendizagem e conhecimento de atividades apropriadas para a classe, de forma a obter um trabalho produtivo.

Diante disso, podemos perceber que são vários fatores que ajudam o futuro professor a desenvolver-se profissionalmente, tais como: os estudos, a articulação entre teoria e prática, a participação em atividades de pesquisa e extensão e as experiências dentro e fora da universidade (PIMENTA; LIMA, 2010). Assim, o estágio, ao possibilitar que o aluno se insira no ambiente escolar, abre espaço para que conheça a realidade e o trabalho do professor e vá aprendendo a partir de uma parceria com um professor experiente. E, nesse momento, o aluno continua com suas aulas na universidade e realiza as atividades de estágio na escola. Um momento para refletir sua formação tendo como base a mediação das aprendizagens nos dois espaços - universidade e escola.

\section{O desenvolvimento das atividades de estágio de Ana e Isa: reflexões e aprendizagens}

O desenvolvimento das atividades do estágio na universidade e na escola foi um momento para refletir sobre a docência e começar a aprender a ser professor. Nesse caso, apresentaremos as aprendizagens das estagiárias Ana e Isa e a relação com as professoras supervisoras Vera e Inês.

A estagiária Ana desenvolveu suas atividades de estágio (observação e regência) em duas turmas de $6^{\circ}$ ano com a supervisão da professora Inês. Ana contou na entrevista, que a professora queria que ela realizasse o estágio em suas três turmas (as duas do $6^{\circ}$ ano e uma do $8^{\circ}$ ), pois, como havia solicitado a aposentadoria, já não ia à escola com frequência e, algumas vezes, suas turmas ficavam sem aula. Mas, Ana trabalhava e precisava conciliar seus horários, escolhendo, assim, as duas turmas do $6^{\circ}$ ano. 
$\mathrm{Na}$ entrevista, buscando entender como interagiu com Inês, perguntamos como foi seu contato com a professora supervisora nesse estágio:

\begin{abstract}
Ana: a professora não estava presente todos os dias durante o estágio, mas ela me passou seu número de telefone, para na hora que eu tivesse alguma dúvida, entrasse em contato com ela. E, sempre que podia, ela deixava atividades prontas, no nível das turmas, atividades que ela gostaria que eu aplicasse, na tentativa de me ajudar e não me deixar perdida sobre qual assunto dar. Eu quase não a vi usar o livro [na observação], nem eu usei. Na última semana de estágio que ela me ofereceu o livro e me sugeriu trabalhar com algumas atividades de geometria. Mas, durante todo o estágio ela só apareceu algumas vezes na sala (Entrevista, 2016).
\end{abstract}

A fala de Ana reflete a ausência (física) da professora Inês na sala de aula. Todavia, há de se considerar seu momento atual (esperando a publicação da aposentaria), estando no momento final da sua atividade docente, mesmo assim, preocupou-se em disponibilizar seu telefone para manter o contato com Ana, sobre a disciplina, os conteúdos e a classe. Embora, deixar atividades prontas sem um planejamento conjunto, não pareça ser, numa perspectiva de formação reflexiva, a melhor das alternativas, mas na visão de Inês e, conforme seu momento, essa era a maneira de contribuir com a formação e a aprendizagem da docência de Ana.

No decorrer das discussões, notaremos que essa ausência (física) da professora Inês pode ter dificultado o desenvolvimento das atividades de estágio e, por consequência, influenciado nas aprendizagens de Ana, pois, não tinha um professor experiente, acompanhando suas ações, mediando momentos de reflexões e análises da realidade escolar, como indicam Barreiro e Gebran (2006) e Passerini (2007).

Como a professora Inês ia poucas vezes à escola, Ana teve dificuldade em realizar as dez horas de observação, que deviam anteceder a regência, como forma de preparação, para que pudesse conhecer as turmas, observar como a professora se relacionava com os alunos, como planejava o conteúdo, as dificuldades dos alunos etc. Relatou essa situação na universidade ${ }^{4}$, em conversa com a professora de Estágio Supervisionado III, durante a aula, local de discussão e reflexão sobre as aprendizagens que estavam construindo no estágio/escola. Primeiramente, a professora da disciplina tentou explicar, para os alunos/estagiários, a importância de realizar a observação antes de iniciar a regência e lembrou que para isso, tinha construído um roteiro, juntamente com a turma, para que se

\footnotetext{
${ }^{4}$ Essas conversas sobre o que acontecia no estágio, na escola, ocorriam conforme as visitas da professora de Estágio Supervisionado III, ou seja, ia até a escola e a partir do que observava discutia na aula, na universidade. Como houve uma paralisação das atividades na universidade, essas discussões acabaram deixando de acontecer. Quando as aulas foram retornadas, os alunos/estagiários já haviam concluído as regências na escola.
} 
orientassem durante a observação. Havia percebido que nem todos os alunos/estagiários, como o caso de Ana, haviam cumprido a observação, por isso, tentou mostrar a importância de realizar todas as etapas.

A observação, como explicou, é um momento para aprenderem como o professor organiza suas aulas, mesmo que faça algo que não lhe agrade, pois, poderá levar para sua prática aquilo que gostou das ações do professor ou descartar aquelas que não lhes parecem adequadas (D’AMBROSIO, 2009). Então, esse é um momento de observar tudo, as metodologias utilizadas, a forma como os alunos se comportam, como aprendem, as dificuldades, tudo poderá auxiliar para a hora de realizar o seu planejamento e desenvolver suas aulas. Durante a conversa, a professora falou diretamente sobre a situação de Ana, que além de não ter conseguido cumprir a carga horária da observação, também relatou dificuldades com as turmas, pois os alunos eram agitados e tinham dificuldades de aprendizagem. Por isso, sugeriu que talvez tivesse sido preciso escolher outras turmas e outra professora supervisora, que fosse à escola regularmente. Mas Ana respondeu:

Ana: Não tinha como, aquela professora foi a opção que a escola me deu, o próprio diretor disse que era para eu pegar as turmas dela, porque eles já estavam sem aula, ela faltava muito e ele disse que era a única opção. Eu trabalho ali perto, sempre realizei o estágio ali, não tinha como ir para outra escola, por causa do meu horário (Aula na Universidade, 2016).

Como vemos, Ana foi vista ali, até pelo diretor da escola, como uma alternativa para que aqueles alunos não ficassem sem aula de Matemática, uma substituta da professora Inês, mesmo que por pouco tempo. Tomando conhecimento dessa realidade nos primeiros dias que acompanhamos Ana na escola, perguntamos a Inês, se sentia-se à vontade para receber estagiários na sua sala e como realizava o acompanhamento.

Inês: Gosto de receber estagiários, não vejo nenhum problema. Pelo contrário, até alivia um pouco, a gente descansa um pouco. Embora eu não me afaste, sempre estou presente [...] Eu acompanho parcialmente. No início eu estava mais perto. Porque ela estava chegando, precisava conhecer as turmas [...] Mas é como você presenciou, eu vou lá, deixo ela na turma e depois saio, porque eu gosto de deixar ela à vontade [...] eu gosto de dar essa liberdade de ação dentro da sala de aula (Entrevista, 2016).

Durante nossas observações (para a pesquisa) na escola, a professora Inês acompanhou Ana até a sala de aula duas vezes, mas, só olhava da porta de entrada, para que os alunos soubessem que estava na escola, logo se retirava. Em uma das aulas Ana precisou chamá-la (estava na sala dos professores), para conversar com os alunos, pois estavam agitados e não os 
conseguia controlar. Sobre a justificativa por não acompanhar Ana durante as aulas, mesmo sabendo que não está correto, não podemos julgá-la, pois é a visão de ensino - docência que tinha. Em uma conversa informal, na sala dos professores, Inês contou que os professores também fizeram dessa forma com ela, quando realizou seu estágio durante a graduação e para ela, essa era a melhor forma, deixar os estagiários 'à vontade'.

Com relação às regências, Ana planejou suas aulas, sozinha, seguindo o plano de curso da escola, que indicava os conteúdos matemáticos que seriam trabalhados durante o ano letivo. Vejamos a sequência de conteúdos que Ana lecionou, na ordem em que foram ministrados: sistema de numeração decimal; problemas de contagem; estudo de gráficos; números naturais; reta numérica; porcentagem; plano Cartesiano e números inteiros e simétricos.

Podemos inferir, inicialmente, que Ana, ao planejar os conteúdos que ia ensinar, mobilizou saberes disciplinares (TARDIF, 2002) também chamados de conhecimento da matéria que os professores ensinam (MIZUKAMI, 2006), ou seja, saberes referentes ao conteúdo matemático. Contudo, não tivera acesso ao livro didático ${ }^{5}$ daquele ano escolar, desde o início do estágio, por isso, percebemos alguns equívocos ao organizar os conteúdos das suas aulas. Por exemplo, o estudo dos números naturais deveria ser o primeiro, para depois ensinar os números inteiros e, em seguida, os decimais, seguindo assim, a ordem de composição dos conjuntos numéricos ${ }^{6}$.

Acreditamos, que se a professora Inês acompanhasse Ana no planejamento das aulas, por ter mais experiência ensinando Matemática, poderia ter evitado que isso acontecesse. Quando esse tipo de situação acontece, fica a marca das lacunas no processo de aprender a ser professor e o estágio pode não atingir totalmente seu potencial formador, por não haver alguém que faça as devidas orientações sobre como o aluno/estagiário deve agir no ambiente da sala de aula e, como indica Varizo (2006), essa é uma das barreiras que dificultam a aprendizagem do futuro professor. Entretanto, essa situação também nos faz questionar a forma como os conteúdos matemáticos são tratados na universidade, pois, durante o curso, essa orientação para a organização do conhecimento matemático precisa ser trabalhada.

Durante nossas observações, percebemos que Ana se preparava para a aula. Na maioria das vezes levou a atividade impressa e quando ia fazer um esquema sobre o conteúdo

\footnotetext{
${ }^{5}$ Livro da Coleção: DANTE, L. R. Projeto Teláris: Matemática 6º ano. $1^{\text {a }}$ ed. São Paulo: Ática, 2012.

${ }^{6} \mathrm{O}$ conjunto dos números racionais (decimais) é formado por todos os elementos do conjunto dos números inteiros que, por sua vez, é formado pelos elementos do conjunto dos números naturais. Fonte: IEZZI, G.; DOLCE, O.; DEGENSZAJN, D.; PÉRIGO, R. Matemática: Volume Único. 4a ed. São Paulo: Atual, 2007.
} 
no quadro tinha tudo anotado em seu caderno, então, sobre o planejamento das aulas, percebemos que não teve tantas dificuldades. Todavia, uma das dificuldades foi com relação ao conhecimento sobre os alunos (MIZUKAMI, 2006). Como podemos ver, no trecho a seguir, ao indagarmos sobre como foi sua regência, considerando o conteúdo matemático e a prática pedagógica, nos contou que teve dificuldade, principalmente no controle da turma, para desenvolver a aula.

\begin{abstract}
Ana: Eu não achei fácil [as regências], principalmente essa questão da liderança, do domínio em sala de aula [...] na hora de entrar em sala de aula, aquele domínio da turma, trazer o aluno para a sala, estimular eles a aprenderem aquele conteúdo que eu estava levando, essa parte não foi fácil. Essa questão de ter autoridade na sala de aula. Eu entrava na sala e era como se eu nem existisse, os alunos agiam como se eu nem estivesse ali. Quando a professora entrava ali eles até tinham certo respeito, mas quando era só eu eles não respeitavam [...] Eu ainda não sei como agir quando o aluno se recusa a fazer as atividades. $\mathrm{O}$ aluno dizia - eu não vou fazer, eu não estou a fim - e eu não sabia como conduzir essa situação (Entrevista, 2016).
\end{abstract}

Como podemos ver, as dificuldades de Ana foram com relação àquelas técnicas (coerção, autoridade e persuasão) que Tardif (2002) sugere para o bom relacionamento com os alunos e o controle da turma. Ana não conseguia convencer os alunos que aquela aula era importante, que aqueles conteúdos têm uma função social e que precisavam participar e se comportar para que ela conseguisse ensinar o conteúdo. Disse que não sabia como agir. Talvez, se tivesse a oportunidade de observar mais aulas da professora Inês, antes de iniciar a regência, teria vivenciado esses momentos de agitação e indisciplina dos alunos e poderia ter visto a postura da professora diante desse comportamento, servindo como experiência de como agir nesses momentos (saberes da experiência), embora cada um construa sua experiência. Bem como, se no planejamento tivesse pensado no conteúdo com exemplos do cotidiano, para chamar a atenção dos alunos. Tal condição deveria ser aprendida, também nas aulas/disciplinas durante a graduação. Rompendo assim, com o modelo formativo técnico sem reflexão, baseado no treinamento de habilidades (DINIZ-PEREIRA, 2002).

De modo geral, apesar das dificuldades encontradas durante o estágio, quando perguntamos sobre as aprendizagens que levaria para a prática enquanto futura professora, Ana avaliou que essa experiência contribuiu para a sua formação:

Ana: no final, apesar da indisciplina não ter diminuído quase nada, já me sentia mais segura, até para propor as atividades [...] Foram muitas aprendizagens. O lidar com alunos em diferentes níveis de conhecimento, alguns que sabiam mais, outros menos, com muita dificuldade em Matemática. Então, eu aprendi a trabalhar com a ausência de homogeneidade 
na sala de aula, com alunos em níveis diferentes [...] Além de aprender a chamar a atenção dos alunos, tentar convidá-los para a aula, que foi meu maior desafio (Entrevista, 2016).

Então, ao final do estágio, a maior aprendizagem de Ana foi com relação aos alunos, tal como indica Tardif (2002), pois aprendeu que eles possuem características individuais e o professor precisa saber lidar com isso, conhecer essas diferenças e levar em consideração durante o planejamento e o ensino.

Agora que contamos um pouco sobre a experiência de Ana, vamos trazer as vivências da estagiária Isa que, diferentemente, teve o acompanhamento da professora Vera durante o período de realização do estágio.

Isa desenvolveu suas atividades de estágio (observação e regência) na turma de $9^{\circ}$ ano com a supervisão da professora Vera. Na entrevista, ao perguntarmos como foi o percurso dos estágios que realizou (o contato com as escolas, com as professoras, a escolha da escola), Isa contou porque escolheu, no Estágio Supervisionado III, aquela escola e a professora Vera, para lhe acompanhar e supervisionar.

Isa: no Estágio I, foram 20 horas de observação. Eu fiz em um colégio aqui no mesmo bairro. E assim, particularmente, eu não gostei. Não foi nem pela turma, foi pelo posicionamento da professora [...] Aí quando chegou no próximo estágio, eu decidi que ia procurar outro colégio. Foi aí que conheci a professora Vera [...] que diferença de professor em sala de aula, de comportamento, como tratava os alunos, tudo diferente [...] quando concluí o segundo estágio, falei para ela que o próximo eu fazia questão de fazer com ela novamente $[. .$.$] foi o que aconteceu agora, vim diretamente nesse colégio$ (Entrevista, 2016).

A atitude de Isa foi aquela sugerida pela professora de estágio na conversa com Ana, na universidade. Isa percebeu que aquela professora não ia contribuir com sua formação e aprendizagem. Logo, sua reação foi trocar a escola. A seguir, destacamos as expectativas de Isa com relação ao estágio e o acompanhamento de um professor experiente a partir do seguinte questionamento: como você compreende o papel do professor supervisor de estágio no seu processo de formação?

Isa: a gente vem para o estágio e tem uma professora na sala de aula que está ali para te supervisionar e dar algumas dicas. Eu acho que para encarar a sala de aula sempre tem um processo de adaptação e eu acredito que essa adaptação é, exatamente, o momento do estágio, que a gente conhece o que realmente é a sala de aula [...] Eu digo que a professora com quem eu estou fazendo agora o estágio, está sendo uma base boa para mim, está me ajudando muito, dando muitas dicas [...] para mim, o estágio está sendo 
muito produtivo. Acredito que agora, para começar as regências, já tenho uma base, uma referência (Entrevista, 2016).

A professora Vera foi para Isa um exemplo de como dar uma aula, como relacionar-se com os alunos etc., ou seja, ela aprendeu com as ações da professora e levou isso para sua prática (D’AMBRÓSIO, 2009). Na entrevista com Vera, indagamos sobre a necessidade de acompanhar os estagiários durante as aulas, em que percebemos que vê o estágio como uma etapa importante para a formação do futuro professor e tem consciência do seu papel nesse processo.

Vera: eu acho que estou ali para ajudar, então eu preciso acompanhar como ela está indo. Eu, na verdade, tenho que avaliar esse trabalho dela, até porque como eu vou dar esse retorno a ela se eu não estiver observando? Não é que eu vou ensinar o outro, mas como eu tenho mais experiência, posso dar algumas dicas, tipo - olha, faz dessa forma que fica melhor [...] Até para que ela tenha condições, porque se for uma sala muito indisciplinada, ela já está com uma insegurança que é natural, de quem está começando, e ainda se os meninos ficarem indisciplinados, como é que ela vai agir? (Entrevista, 2016).

Dessa forma, Isa teve um bom relacionamento com a professora Vera. Pôde compartilhar aprendizagens com um professor mais experiente e aprender alguns saberes que, como indica Tardif (2002), esses professores podem compartilhar, tais como dicas sobre o comportamento dos alunos, de como lidar com a indisciplina etc.

Outro diferencial no estágio de Isa foi a oportunidade de planejar as aulas com Vera. $\mathrm{Na}$ escola, o momento dos professores reunirem-se para planejar acontecia a cada 15 dias, então, Isa participou de dois encontros. Vera entregou alguns livros e mostrou algumas atividades que podia utilizar. Isa também ajudou a elaborar a prova que os alunos iam fazer sobre aquele conteúdo que ela havia trabalhado.

Durante o período da regência, Isa trabalhou com os seguintes conteúdos matemáticos: relações métricas no triângulo retângulo; Teorema de Pitágoras e construção de triângulos; tipos de triângulos; trigonometria no triângulo retângulo e ângulos notáveis. Percebemos que Isa não teve dificuldade na organização e planejamento do conteúdo matemático (saber disciplinar), pois, teve o suporte da professora Vera durante todo processo.

Apesar de toda orientação de Vera, Isa contou que não foi tão fácil planejar as aulas, considerando o conteúdo matemático. Pois, quando a questionamos se o aprendizado construído na universidade é apropriado para o ensino na educação básica, contou que durante 
suas experiências no estágio, percebeu que a Matemática ensinada na universidade não é apropriada para esse ensino e precisou estudar aqueles conteúdos novamente.

Isa: a gente fica tão atarefado, são disciplinas tão pesadas, com muitos cálculos, que não vai aproveitar no ensino básico e a gente fica tão preocupado com aquilo ali [...] que quando chega no estágio, tem que estudar, porque sente falta, tem que voltar e estudar os conteúdos da Educação Básica (Entrevista, 2016).

Esse relato reflete o que Lübeck e Souza (2012) indicam, que a formação das licenciaturas em Matemática apoiadas somente no conhecimento técnico, tem-se mostrado ineficaz para o ensino de Matemática, ou seja, vemos a necessidade de repensar a forma como esse saber disciplinar vem sendo trabalhado na formação do professor de Matemática que irá atuar, provavelmente, na Educação Básica.

Ao final do estágio, após ter concluído o período da regência, perguntamos à Isa o que levaria de aprendizagem do estágio para a sua prática enquanto futura professora, e ela nos contou como foi essa experiência e quais aprendizagens haviam lhe marcado.

Isa: A primeira coisa que me faz pensar é que a gente tem que ter muita paciência, isso eu não tinha. Eu percebi que a sala de aula acaba se tornando algo repetitivo, com relação ao comportamento dos alunos, você chama a atenção deles e em questão de três minutos o mesmo aluno já está fazendo a mesma coisa. Então, se não tiver autocontrole e paciência, você acaba voltando para casa bem desanimado [...] Depois vem outras coisas. Domínio do conteúdo também é fundamental, uma boa relação entre professor e alunos [...] eu percebi que se não há uma boa relação, cria-se uma rivalidade entre o aluno e o professor e isso não é bom [...] A questão de demonstrar bastante na Matemática, trazer muitos exemplos, estar preparado para tirar todas as dúvidas do aluno, tem que estudar, não esperar que vai passar só aquilo que está no seu caderno e pronto, porque os alunos vão ter outras dúvidas. Tudo isso eu aprendi (Entrevista, 2016).

Nessa fala de Isa, fica nítido a mobilização de diversos saberes e conhecimentos docentes, que foram oportunizados durante o estágio, que vão desde os saberes disciplinares, referente ao conteúdo matemático, àqueles produzidos a partir do relacionamento com professores, na experiência do dia a dia da sala de aula, na forma de ensinar o conteúdo etc. (TARDIF, 2002; MIZUKAMI, 2006).

Nesse estágio, as alunas/estagiárias também puderam mobilizar os saberes pedagógicos e possibilitamos que refletissem sobre isso, ao questionarmos sobre quando estavam preparando a aula ou no seu desenvolvimento, se perceberam alguma relação entre os conhecimentos específicos e pedagógicos que aprenderam na universidade. Como podemos 
observar, esses saberes estavam presentes durante o planejamento e na prática em sala de aula.

Ana: até as teorias que a gente estudou e que muitos [colegas] acharam que não ia ajudar, os grandes teóricos da Educação, a Educação Libertadora de Paulo Freire, por exemplo, que você acha que nunca vai usar. Mas depois, quando entra na sala de aula que você vê a importância de todas as disciplinas pedagógicas. Até a organização do trabalho pedagógico [disciplina], que ensina a montar uma sequência didática, fazer um plano de aula, a gente aprendeu tudo isso lá atrás, há dois anos (Entrevista, 2016).

Isa: quando a gente está planejando a aula, mesmo em casa, sempre vem na mente o que estudou nas disciplinas pedagógicas, o que a gente pode usar [...] a todo momento a gente usa [...] Teve uma disciplina que eu gostei de fazer, que me ajuda muito, foi a de 'Formação do Professor de Matemática', que deu uma base boa. A disciplina 'Didática' também, que dão um suporte para a hora que a gente está pensando a prática (Entrevista, 2016).

Isso é importante, pois é preciso que o aluno/estagiário tenha consciência que para ensinar, não basta apenas o conhecimento disciplinar, do conteúdo, é necessário pensar nas formas de ensinar esse conteúdo (como, porque e para que) e no contexto dessa aprendizagem, próprias do saber pedagógico (TARDIF, 2002; MOURA, 2011).

\section{Considerações finais}

Apresentamos a experiência de duas alunas/estagiárias que, inicialmente, possuíam o mesmo perfil (com relação a prática docente), ambas estavam pela primeira vez na sala de aula ensinando Matemática, pois, nos estágios anteriores, tinham realizado observações, monitorias e oficinas. Assim, o estágio foi, para elas, a oportunidade de aprenderem a ser professoras no contexto da escola e da sala de aula.

Diante disso, em resposta ao objetivo proposto no início desse artigo, identificamos que Ana sentiu a falta da supervisão e acompanhamento diário da professora Inês, para orientá-la quanto ao conteúdo matemático que devia ser ensinado, ajudar e ensiná-la a controlar os alunos, lidar com a indisciplina, elaborar propostas adequadas àquele nível de ensino etc., enquanto que Isa, não teve essas dificuldades, talvez porque observou a professora durante várias aulas e, assim, aprendeu como planejava os conteúdos, os tipos de atividades, como se relacionava com os alunos, então, quando foi sua vez de realizar a regência, sentiu-se mais preparada. 
Por tanto, evidenciamos que as ações do professor supervisor de estágio são importantes, na medida em que proporcionam a mobilização de saberes e conhecimentos docentes pelo aluno/estagiário, pois, pode compartilhar suas experiências sobre organização da classe, planejamento das aulas, relação com alunos, o ensino da Matemática etc., e oportunizar que esse a futuro professor, inserido no ambiente da escola, faça reflexões sobre sua prática docente.

Concluindo, retomamos Tardif (2002) quando nos diz que, o saber do professor não é um saber acabado, pois vai sendo construído ao longo de sua carreira profissional. Este estágio foi uma oportunidade para Ana e Isa sentirem-se professoras, começando a assumir responsabilidades docentes. Assim, a presença e supervisão do professor da Educação Básica, durante o estágio, na escola, nas situações que permeiam a docência - planejamento, conteúdo, atividades etc. - contribuem para reflexão e construção dos saberes docentes ainda na formação inicial (BARREIRO; GEBRAN, 2006), aprendendo a ser professor na ação (PIMENTA; LIMA, 2010), por meio da mobilização e troca de saberes entre os professores experientes (TARDIF, 2002) e as alunas/estagiárias - futuras professoras de Matemática, visto que estão aprendendo a ensinar não um conteúdo, mas um modo de apreender conteúdos, uma metodologia de interagir no mundo, próprio do saber pedagógico (MOURA, 2011).

\section{Referências}

BARREIRO, Iraide Marques de Feitas; GEBRAN, Raimunda Abou. Prática de ensino e estágio supervisionado na formação de professores. São Paulo: Avercamp, 2006.

\section{BRASIL. Diretrizes Curriculares Nacionais para os Cursos de Matemática, Bacharelado e Licenciatura. Parecer CNE/CES 1.302/2001. Brasília, 6 de novembro de 2001.}

D’AMBRÓSIO, Ubiratan. Educação matemática: da teoria à prática. $17^{\mathrm{a}}$ ed. Campinas/SP: Papirus, 2009.

DINIZ-PEREIRA, Júlio Emilio. A pesquisa dos educadores como estratégia para construção de modelos críticos de formação docente. In: PEREIRA, Julio Emilio Diniz; ZEICHNER, Kenneth M. A pesquisa na formação e no trabalho docente. Belo Horizonte: Autêntica, 2002. p. 11-42.

LÜBECK, Kelly Roberta Mazzutti; SOUZA, José Ricardo. Pesquisa em matemática e em educação matemática: desafios para uma "nova" Educação a partir de diferentes pontos de vista. Educação Matemática em Revista - RS. Rio Grande do Sul (RS), v. 1, n. 13, p. 17-23, 
2012. Disponível em: http://www.sbemrs.org/revista/index.php/2011_1/article/view/45. Acesso em 24 jan. 2017.

MIZUKAMI, Maria das Graças Nicoletti. Aprendizagem da docência: conhecimento específico, contexto e práticas pedagógicas. In: NACARATO, Aldair Mendes; PAIVA, Maria Auxiliadora Vilela (Org.). A formação do professor que ensina matemática: perspectivas e pesquisas. Belo Horizonte: Autêntica, 2006. p. 213-231.

MOURA, Manoel Orisovaldo de. Educar con las matemáticas: saber específico y saber pedagógico. Educación y Pedagogía, Medellín, Universidad de Antioquia, Facultad de Educación, vol. 23, núm. 59, enero-abril, 2011, pp. 47-57. Disponível em:

http://aprendeenlinea.udea.edu.co/revistas/index.php/revistaeyp/article/view/869. Acesso em 17 nov. 2016.

PASSERINI, Gislaine A. O estágio supervisionado na formação inicial de professores de matemática na ótica de estudantes do curso de licenciatura em matemática da UEL.

121f. Dissertação (Mestrado em Ensino de Ciências e Educação Matemática) - Universidade Estadual de Londrina. Londrina: UEL, 2007.

PIMENTA, Selma Garrido; LIMA, M. S. L. Estágio e docência. $6^{\text {a }}$ ed. São Paulo: Cortez, 2010.

TARDIF, Maurice. Saberes Docentes e Formação Profissional. Petrópolis: Vozes, 2002.

VARIZO, Zaíra da Cunha Melo. Os caminhos da didática e sua relação com a formação de professores de matemática. In: NACARATO, Aldair Mendes; PAIVA, Maria Auxiliadora Vilela (Org.). A formação do professor que ensina matemática: perspectivas e pesquisas. Belo Horizonte: Autêntica, 2006. p. 43-59.

\section{$\underline{\text { SOBRE AS AUTORAS }}$}

\section{Jéssica Mistura Zanon}

Mestre em Educação Matemática. Universidade Estadual de Santa Cruz (UESC). Integrante do "Grupo de Pesquisas em Matemática, Estatística e em Ciências" (GPEMEC/ UESC/ Programa de Pós-Graduação em Educação Matemática - PPGEM). E-mail: jessica.zanon@hotmail.com

\section{Maria Elizabete Souza Couto}

Doutora em Educação pela Universidade Federal de São Carlos (UFSCAR). Professora titular da Universidade Estadual de Santa Cruz (UESC/BA). Integrante do "Grupo de Pesquisas em Matemática, Estatística e em Ciências” (GPEMEC/ UESC/Programa de Pós-Graduação em Educação Matemática - PPGEM). E-mail: melizabetesc@gmail.com 